University of Nebraska - Lincoln

DigitalCommons@University of Nebraska - Lincoln

U.S. Air Force Research

U.S. Department of Defense

2013

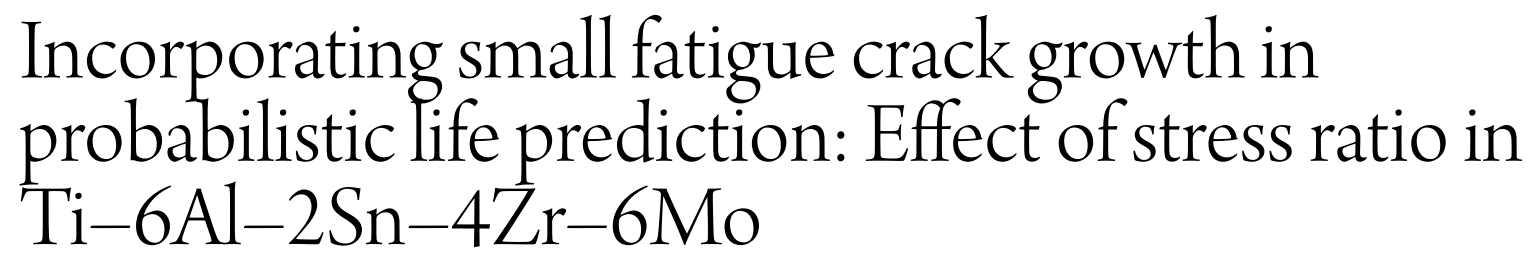

Sushant K.Jha

Wright-Patterson Air Force Base, Universal Technology Corporation

Reji John

Wright-Patterson Air Force Base

James M. Larson

Wright-Patterson Air Force Base

Follow this and additional works at: http:// digitalcommons.unl.edu/usafresearch

Jha, Sushant K.; John, Reji; and Larson, James M., "Incorporating small fatigue crack growth in probabilistic life prediction: Effect of stress ratio in Ti-6Al-2Sn-4Zr-6Mo" (2013). U.S. Air Force Research. 64.

http://digitalcommons.unl.edu/usafresearch/64

This Article is brought to you for free and open access by the U.S. Department of Defense at DigitalCommons@University of Nebraska - Lincoln. It has been accepted for inclusion in U.S. Air Force Research by an authorized administrator of DigitalCommons@University of Nebraska - Lincoln. 


\title{
Incorporating small fatigue crack growth in probabilistic life prediction: Effect of stress ratio in Ti-6Al-2Sn-4Zr-6Mo
}

\author{
Sushant K. Jha ${ }^{\mathrm{a}, \mathrm{b}, *}$, Reji John ${ }^{\mathrm{a}}$, James M. Larsen ${ }^{\mathrm{a}}$ \\ ${ }^{a}$ U.S. Air Force Research Laboratory, Materials and Manufacturing Directorate, AFRL/RXCM, Wright-Patterson Air Force Base, OH 45433, United States \\ ${ }^{\mathrm{b}}$ Universal Technology Corporation, Dayton, $\mathrm{OH} 45432$, United States
}

\section{A R T I C L E I N F O}

\section{Article history:}

Received 2 July 2012

Received in revised form 2 January 2013

Accepted 7 January 2013

Available online 1 February 2013

\section{Keywords:}

Small fatigue crack

Stress ratio

Ti-6Al-2Sn-4Zr-6Mo

Life prediction

\begin{abstract}
A B S T R A C T
The effect of stress ratio on the statistical aspects of small fatigue crack growth behavior was studied in a duplex microstructure of Ti-6Al-2Sn-4Zr-6Mo (Ti-6-2-4-6) at $260{ }^{\circ} \mathrm{C}$ with particular emphasis on incorporating small-crack data into probabilistic life prediction and the influence of stress ratio on probabilistic lifetime limits. A Focused Ion Beam (FIB) was used to machine micro-notches in test specimens, which served as crack-initiation sites and enabled the acquisition of multiple small-crack growth data sets from single experiment. Stress ratios of $-0.5,0.05$, and 0.5 were employed, and small-crack growth was monitored by the acetate replication method. Qualitatively, change in the stress ratio produced almost negligible influence on the small-crack growth behavior when plotted as crack growth rate $(\mathrm{d} a / \mathrm{d} N)$ vs. applied stress intensity factor range $(\Delta K)$. A probabilistic method was employed to represent the variability in the small-crack growth behavior and the statistical differences with respect to stress ratio where a method of optimization of the small-crack growth model parameters, based on a minimization of the error between the predicted and the measured crack length vs. cycles ( $a$ vs. $N$ ) data, was used. In spite of qualitative similarity, differences in the statistical parameters of small-crack growth as a function of stress ratio were found to be significant in life prediction. The methods for representation and probabilistic treatment of small-crack data were also shown to be important factors in incorporation of the small-crack regime in probabilistic life prediction.
\end{abstract}

(c) 2013 Elsevier Ltd. All rights reserved.

\section{Introduction}

Accurate characterization and understanding of the effect of stress ratio $(R=$ minimum/maximum stress) on fatigue crack growth are important from several life prediction considerations. For example, under loading profiles of practical interest, such as spectrum loading, the $R$ effect or the mean-stress effect on crackgrowth behavior is a critical input in lifetime calculations [1-3]. Similarly, an accurate representation of the $R$ effect is required in problems where the crack grows through regions of varying stress state, such as a weld zone [4,5], under a residual stress field introduced by surface treatments [6,7], and crack growth from geometric features [8].

The effect of $R$ on the long-crack growth behavior has been studied extensively. In the long-crack regime, the degree of the $R$ effect varies, depending on the material $[9,10]$. In metallic materials, the effect is found to be more pronounced in the near-threshold crack-growth-rate regime, which is often rationalized in terms

* Corresponding author at: U.S. Air Force Research Laboratory, Materials and Manufacturing Directorate, AFRL/RXCM, Wright-Patterson Air Force Base, OH 45433, United States. Tel.: +1 9372550388; fax: +1 9376564840.

E-mail addresses: sushant.jha@wpafb.af.mil, sushantjha@hotmail.com (S.K. Jha). of the crack closure arguments [11-15]. The crack closure effects are thought to decrease with increasing $R$, producing a shift in the long-crack growth curve towards higher growth rates [1115] when plotted in terms of the applied stress intensity factor range, $\Delta K$. It has been shown in such cases that the $R$ effect on long-crack growth largely diminishes when data are plotted in terms of the closure-corrected, effective- $\Delta K$ ( $\left.\Delta K_{\text {eff }}\right)$ [11-15]. Although crack closure appears to explain the $R$ effect in many cases, other mechanisms have also been shown to be important [16-20]. These mechanisms largely stem from the recognition that, under certain loading regimes, $\Delta K$ does not uniquely represent the driving force for long-crack growth but contributions of other parameters such as the maximum stress intensity factor, $K_{\max }$ need to be represented [16-20]. Thereby, the effect of $R$ on long-crack growth has also been explained by mechanisms involving static fracture modes such as sustained load cracking that are promoted by $K_{\max }$ [16-20]. Some mechanisms of sustained load cracking that have been proposed for titanium alloys include stress-assisted hydride formation and creep-assisted crack growth [18].

Small fatigue cracks, which by one definition are cracks whose dimensions are on the order of the microstructural size scale, have long been recognized to grow below the long-crack growth threshold and faster than a long-crack at the same nominal $\Delta K[21-25]$. 
As such, small-crack growth constitutes a vital regime in fatigue life prediction. This is not only because a purely long-crack based prediction can often be non-conservative, especially in the long-lifetime domain [26,27], but also due to the consideration that a significant fraction of lifetime after crack initiation can be spent in the smallcrack regime $[27,28]$. The importance of appropriately accounting for the small-crack growth regime in life prediction is further accentuated by the observation that, in many cases, the influence of a variable on the small-crack behavior is different than its effect on the long-crack growth $[29,30]$. Additionally, the small-crack behavior exhibits a stronger influence of microstructure [22,24], which is manifested as larger fluctuations in growth rate than is seen in the long-crack regime, as well as greater variability in growth between different small-cracks in nominally identical material.

The above factors suggest that the small-crack regime should be a crucial ingredient in probabilistic modeling of fatigue lifetime, and recent emphasis on physics-based probabilistic life-prediction methods [31] has generated a renewed focus on small-crack growth. However, although the small-crack effects are considered important for accurate probabilistic life prediction, incorporation of this regime in life prediction is partly hampered by the very nature of small-crack data, which, as discussed above, is marked by fluctuations in growth rate and variability in growth between different cracks. A lack of sufficient attention in the literature to quantitative representation of the small-crack regime and the effect of microstructure and loading variables, such as $R$, on the statistical parameters of small crack growth has further limited an explicit inclusion of small-crack data in probabilistic life prediction models.

From a purely crack closure argument, one might expect an almost negligible $R$ effect on growth rates of small fatigue cracks, since crack closure is considered largely a crack-wake effect, whereas the wake is thought to not have fully developed in the small-crack regime [21,22]. A lack of significant influence of $R$ in the small-crack regime is also supported by a recent study on $\mathrm{Ti}-$ $6 \mathrm{Al}-4 \mathrm{~V}$ (Ti-6-4) [32]. Other researchers have shown that the long-crack behavior at a high $R$, where the crack closure effects are considered essentially negligible, encloses the small-crack data at lower $R$ values $[33,34]$. Methods for fatigue design thresholds, based on these aspects of the effect of $R$ on small vs. long crack growth, have been developed [33,34]. Additionally, models of plasticity-induced crack-closure that correlate the effect of $R$ on the long-crack growth and account for the small-crack behavior have been proposed and applied to fatigue life prediction [28]. These approaches have provided valuable insights into the limiting $\Delta K$ conditions and methods for design of fracture critical structures.

While above methods are significant for incorporating smallcrack growth in fatigue design, to enable probabilistic life prediction models, also needed are methods that address the quantitative representation of the small-crack growth data and variability in growth rates, including the effect of $R$ (and other variables). Some recent studies have proposed a mechanism-based probabilistic model of life-limiting fatigue behavior, which demonstrated that small-crack growth can be used to predict the life-limiting failure distribution $[29,35,36]$. From a probabilistic life prediction perspective, the questions of sensitivity of lifetime to variation in statistical parameters of small-crack growth behavior and the data reduction method are considered important, and this paper is focused on these aspects of small-crack growth. In this regard, the effect of $R$ on the small-crack growth behavior, both in terms of the average growth rates as well as the variability in the same, in the $\alpha+\beta$ titanium alloy, Ti-6Al-2Sn-4Zr-6Mo (Ti-6-2-4-6) was studied at $260^{\circ} \mathrm{C}$. A probabilistic method was used to represent the small-crack growth behavior, which was applied in a previously proposed life-prediction model $[29,35,36]$ to determine the effect of $R$ on the distribution in lifetime and the probabilistic life limits. The data reduction method and the model representation of $\mathrm{d} a / \mathrm{d} N-\Delta K$ relationship are important components of quantitative representation of the small-crack behavior. In this regard, two methods for obtaining a model representation of small-crack growth were examined and the effects of the measurement error, frequency of data collection, and the maximum crack length, on the modeled $\mathrm{d} a / \mathrm{d} N-\Delta K$ curves were also evaluated.

\section{Materials and experimental procedure}

\subsection{Material}

The material in this study was the $\alpha+\beta$ titanium alloy, Ti-6Al$2 \mathrm{Sn}-4 \mathrm{Zr}-6 \mathrm{Mo}$. The alloy was obtained in the $\alpha+\beta$ processed and heat treated condition, which produced the duplex microstructure shown in Fig. 1. The microstructure consisted of primary, equiaxed $\alpha\left(\alpha_{\mathrm{p}}\right)$ particles, and lamellar secondary- $\alpha / \beta$ colonies. The average size of $\alpha_{\mathrm{p}}$ was about $4 \mu \mathrm{m}$ and that of colonies was about $15 \mu \mathrm{m}$. The volume fractions were approximately 0.3 and 0.7 , respectively, of $\alpha_{p}$ and the colony phase. Further details on the microstructure are provided in [35]. The tensile behavior of this microstructure at $260{ }^{\circ} \mathrm{C}$ is shown in Fig. 2 . The $0.2 \%$ yield strength was about $850 \mathrm{MPa}$ and the ultimate tensile strength was about $1010 \mathrm{MPa}$.

\subsection{Experimental procedure}

\subsubsection{Small-crack growth testing}

The small-crack growth tests were conducted using an MTS servo-hydraulic test system equipped with a 458 controller. The tests were performed in load control, and the specimens were axially loaded at a frequency of $20 \mathrm{~Hz}$ at $260{ }^{\circ} \mathrm{C}$ in lab air atmosphere. Three stress ratios, $R\left(\sigma_{\min } / \sigma_{\max }\right)=-0.5,0.05$, and 0.5 , were used.

The fatigue specimens had a round-bar geometry with a uniform gauge section of about $4.0 \mathrm{~mm}$ diameter and a gauge length of about $12.5 \mathrm{~mm}$. The final machining step was low stress grinding (LSG). Specimens were electropolished to remove about $25 \mu \mathrm{m}$ of the surface layer in order to minimize any effect of LSG-induced residual stress and to provide a uniformly smooth surface for observation and measurement of small cracks. Nine micro-notches were machined in each specimen using a Focused Ion Beam (FIB) to create crack initiation sites and to enable multiple small-crack measurements from each specimen. The placement scheme of FIB micro-notches was similar to that reported in [32]. The micro-notches were arranged in three columns, each containing 3 notches, where the columns were separated by $120^{\circ}$ around

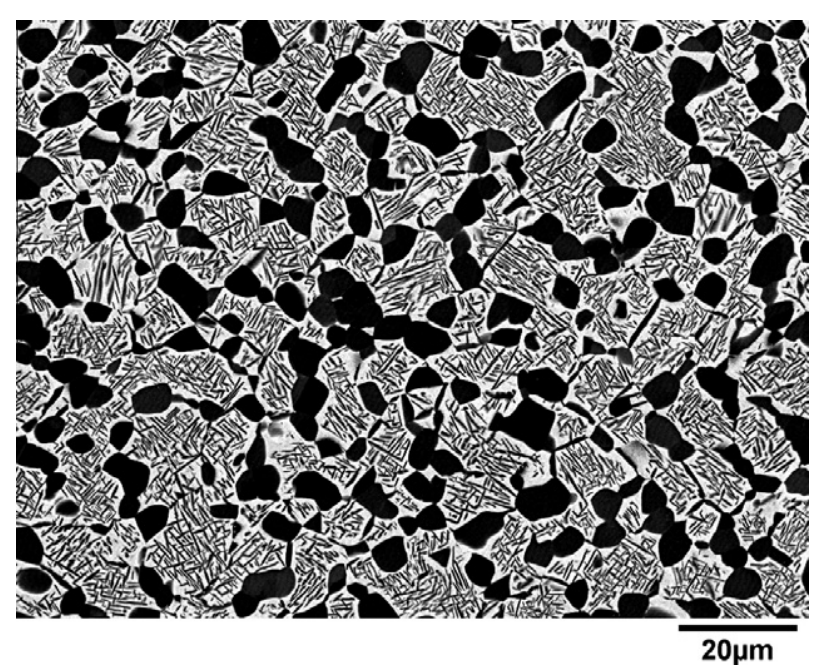

Fig. 1. A back-scattered electron image of the microstructure of the Ti-6-2-4-6 alloy employed in this study. 




Fig. 2. Tensile behavior of Ti-6-2-4-6 at $260^{\circ} \mathrm{C}$.

the specimen circumference. The spacing between notches in a given column was $3 \mathrm{~mm}$. Further, the three columns were staggered by $1 \mathrm{~mm}$ with respect to each other so that only one notch was present on any given plane. An example of a FIB-machined micro-notch is presented in Fig. 3. In the overview fractograph of Fig. 3a, a fatigue crack that initiated from a FIB notch in one of the small-crack growth specimens (tested at $R=0.5$ ) is shown at final fracture. Since the test was conducted at $260^{\circ} \mathrm{C}$, the crack faces exposed to the atmosphere for extended period are heat-tinted due to oxidation. This can be seen by the contrast difference between the fatigue crack growth regime and the fracture region. This figure indicates that the crack aspect ratio (i.e., depth/ half surface-arc length) approximately equaled 1 . The higher magnification image focused at the origin of the same crack is presented in Fig. 3b, and shows that the crack emanated from the FIB notch. The notch was rectangular, with the depth approximately half the surface length, however, the crack growing from the notch is assumed to quickly attain a semi-elliptical shape.

A Goodman Diagram approach [37] was used to obtain a rough estimate of the equivalent maximum applied stress levels $\left(\sigma_{\max }\right)$ at various $R$ values. The Goodman line or the constant lifetime line is shown in Fig. 4 where $\sigma_{\max }$ of $860 \mathrm{MPa}$ at $R=0.05$ is taken as the baseline condition. It is recognized that the Goodman line as shown here is only an approximation of a constant-lifetime line, and several modifications to this model have been proposed [38]. However, for the purposes of determining equivalent stress levels, and appropriate combinations of $R$, applied stress level and notch size for successful small-crack growth tests, this approach can be used to obtain reasonable estimates. The intersection points between the Goodman line and lines corresponding to $R=-0.5$ and 0.5 give the approximate equivalent applied stress levels at these stress ratios. The corresponding $\sigma_{\max }$ values applied in the smallcrack growth tests are given in Table 1 .

Using $R=0.05$ as the baseline, a notch depth of $5 \mu \mathrm{m}$ was sufficient to produce crack initiation at a majority of notches at $\sigma_{\max }=860 \mathrm{MPa}$. The corresponding initial stress intensity factor range $(\Delta K)$ for a semi-elliptical crack of the same depth is about $2.13 \mathrm{MPa} \sqrt{ } \mathrm{m}$, as given in Table 1 . The desired initial crack depths, needed to produce the initial $\Delta K$ of $2.13 \mathrm{MPa} \sqrt{ } \mathrm{m}$ at $R=-0.5$ and 0.5 , are also listed in Table 1 . Based on this reasoning, notch depths of 5 and $15 \mu \mathrm{m}$ (with the surface length, 2c, being twice the depth) were utilized at $R=-0.5$ and 0.5 respectively. As indicated in Table 1 , small cracks initiated from a majority of micro-notches under each of the three combinations of $R, \sigma_{\max }$, and initial notch size.

The small-crack growth was monitored by the standard acetate replication method [39]. Tests were periodically interrupted and

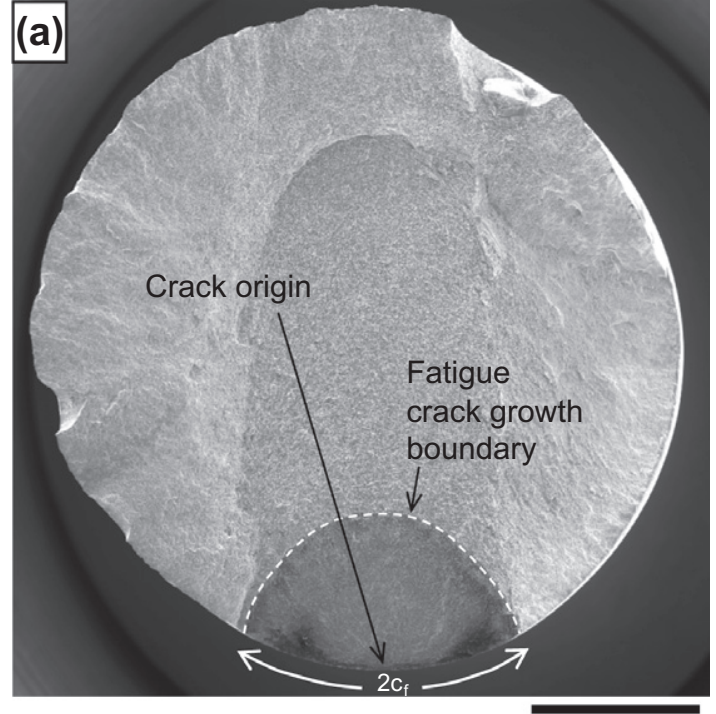

$1 \mathrm{~mm}$



Fig. 3. FIB machined micro-notch at a fatigue crack origin of a small-crack growth specimen tested at $R=0.5$; (a) an overview of the crack that initiated from the FIB micro-notch at the time of final fracture $\left(2 c_{\mathrm{f}}=\right.$ crack length at fracture $)$ and (b) crack origin.

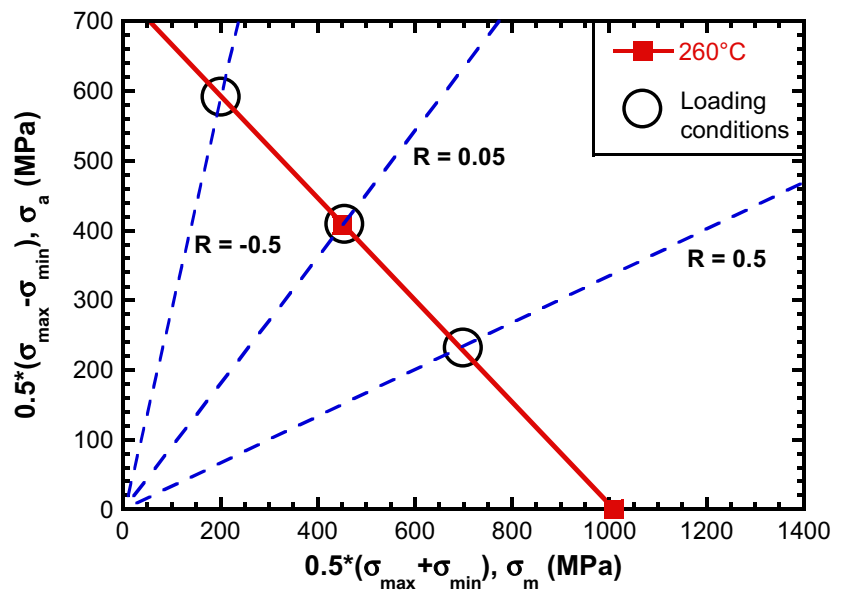

Fig. 4. Goodman diagram approach to estimate the maximum stress levels at various $R$. 
Table 1

Estimation of FIB notch depths and maximum stress levels at various $R$.

\begin{tabular}{|c|c|c|c|c|c|}
\hline$R$ & $\begin{array}{l}\sigma_{\max }(\text { Goodman }) \\
(\mathrm{MPa})\end{array}$ & $\begin{array}{l}\Delta K \text { for the notch depth of } 5 \mu \mathrm{m} \\
(\mathrm{MPa} \sqrt{ } \mathrm{m})\end{array}$ & $\begin{array}{l}\text { Notch depth for } \Delta K=2.13 \\
(\mu \mathrm{m})\end{array}$ & $\begin{array}{l}\text { Notch depth employed } \\
(\mu \mathrm{m})\end{array}$ & $\begin{array}{l}\text { Fraction of notches that initiated a } \\
\text { crack }\end{array}$ \\
\hline-0.5 & 805 & 2.11 & 5.1 & 5 & 0.9 \\
\hline 0.05 & 860 & 2.13 & 5.0 & 5 & 0.8 \\
\hline 0.5 & 925 & 1.20 & 15.6 & 15 & 1 \\
\hline
\end{tabular}

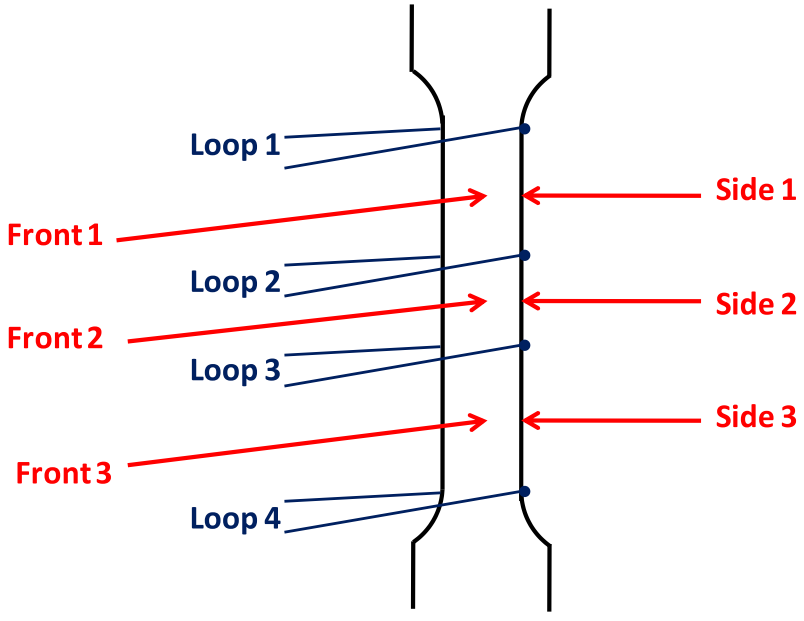

Fig. 5. Schematic illustration of the locations of loop thermocouples (which were used to control the temperature in an actual test) and welded thermocouples in a dummy specimen that was used to test the temperature profile.

the specimen was cooled to room temperature for replication. Replicas were obtained at $60 \%$ of the maximum load in a fatigue cycle. An optical microscope was used to measure crack lengths from replicas.

\subsubsection{Heating system}

As stated previously, the small-crack growth tests were conducted at $260{ }^{\circ} \mathrm{C}$. A collet gripping mechanism was used with MTS hydraulic grips to load the specimens. A four-zone quartzlamp heating system was employed to stabilize specimens at the test temperature. Temperatures were independently controlled and monitored at four points along the gauge length and two points outside the gauge on both ends of the specimen. Loop thermocouples, that were spring loaded to maintain contact with the specimen, were used in the gauge section. Fig. 5 represents the thermocouple configuration in a dummy specimen which was used to verify the heating system. In the dummy specimen, the loop thermocouples were placed in the same configuration as in an actual test, but extra thermocouples were welded to the "side" and "front" of the specimen, as illustrated by arrows in the figure. A plot of the stabilized temperature profile, i.e., after the ramp-up period, in the gauge section as recorded by these thermocouples is shown in Fig. 6. The temperatures were recorded for duration typical of a fatigue test and found to be very stable at each measurement location throughout the entire time. As shown in the figure, the temperature readings were within $\pm 3{ }^{\circ} \mathrm{C}$ of the set point, and the loop thermocouple readings were in close agreement with those of the welded thermocouples.

\section{Small-crack growth data reduction}

\subsection{K-solution}

The $K$-solution by Raju and Newman [40] for a semi-elliptical surface crack in a rod was used in this study. The solution at the surface tip of the crack was employed, which is given by [40]:

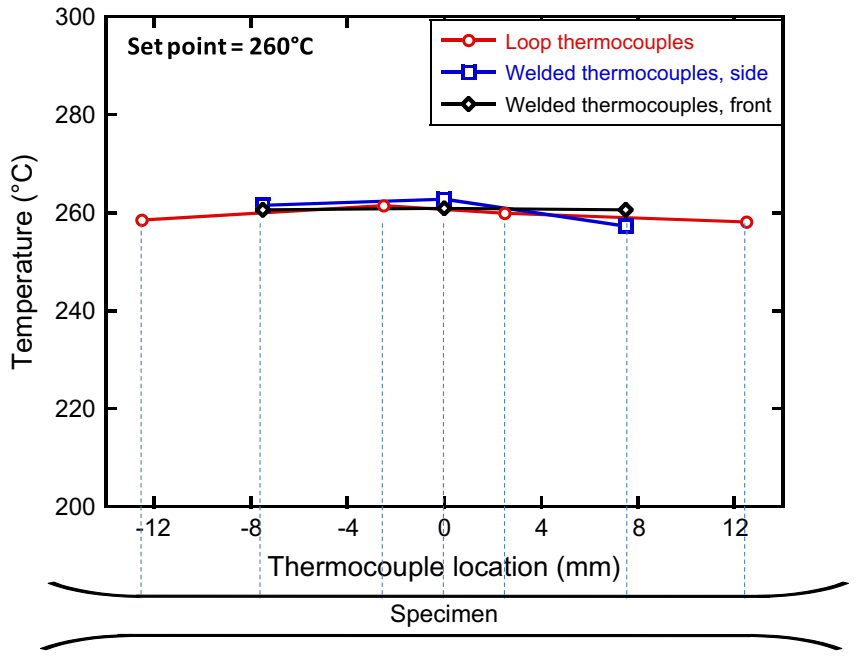

Fig. 6. Temperature readings from the loop and welded thermocouples in a dummy specimen.

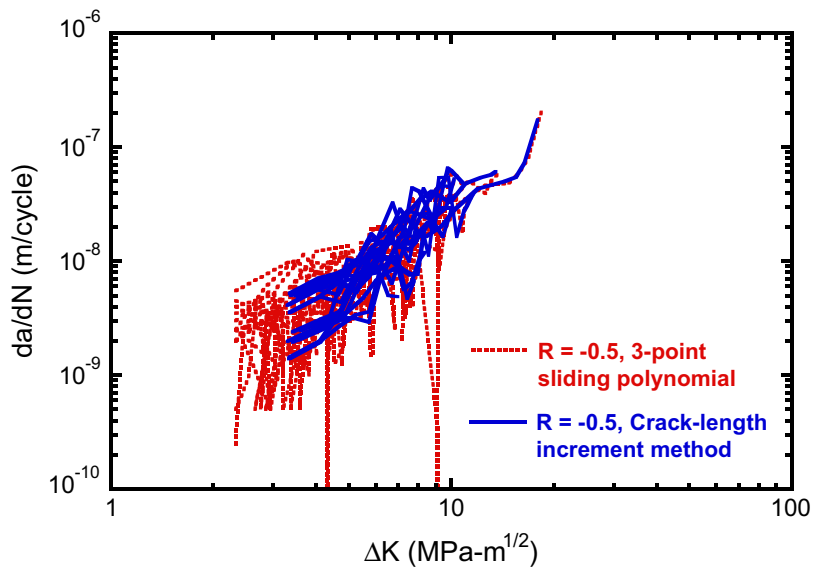

Fig. 7. A comparison of small fatigue crack data reduction by the 3-point sliding polynomial and crack-length increment methods $(R=-0.5)$.

$K=S \sqrt{\frac{\pi a}{Q}} F$

where $S$ is the applied stress level, a is the crack depth, $Q$ is the shape factor for an ellipse, and $\mathrm{F}$ is the boundary correction factor [40]. The crack aspect ratio, a/c of 1 was assumed for which $Q=2.464$. The values of $F$ at the surface tip were tabulated in [40] as a function of normalized crack size, $a / D$ where $D$ is the rod diameter. A 2nd order polynomial fit to this tabular data was used as a representation of the factor, $F$, which was: $F\left(\frac{a}{D}\right)=1.445+$ $0.0727\left(\frac{a}{D}\right)+2.5016\left(\frac{a}{D}\right)^{2}$. For positive $R, \Delta K$ was given by the Maximum $K$-Minimum $K\left(K_{\max }-K_{\min }\right)$ in a fatigue cycle, but, for 


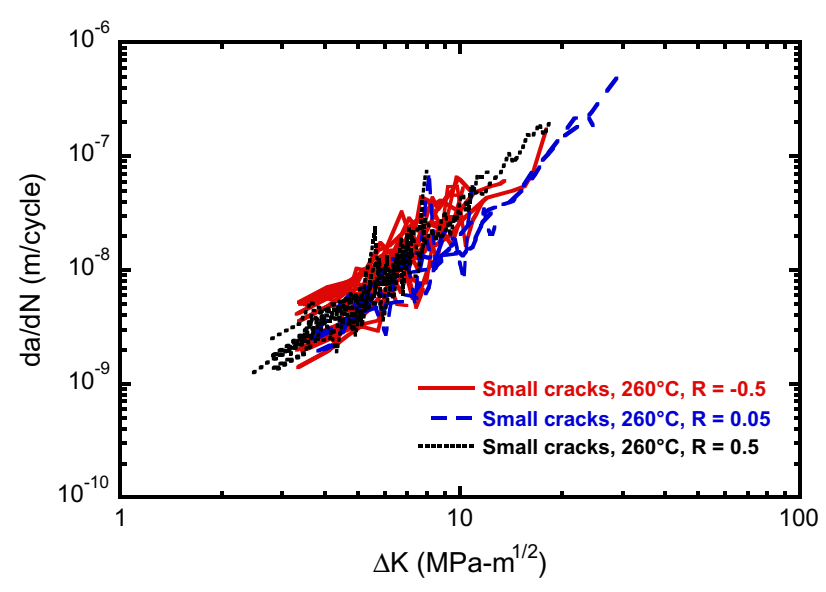

Fig. 8. Effect of $R$ on the small crack growth behavior in Ti-6-2-4-6 at $260{ }^{\circ} \mathrm{C}$.

negative $R$, only the positive portion of the loading cycle was included in $\Delta K$, i.e., $\Delta K$ was taken as $K_{\max }$.

\subsection{Calculation of growth rates}

Typically, the small-crack growth behavior shows more variability than the long-crack regime, due to stronger influence of interactions of the crack front with the local microstructure $[21,22]$. This variability is reflected both in terms of differences in growth rates between cracks, as well as fluctuations in growth rate of a given crack. Since the small cracks are on the order of the microstructural size scale, and extension of a crack in a given fatigue loading interval can be on the sub-micrometer to the micrometer scale, the accuracy of measurement together with the frequency of data collection have a strong bearing on the calculated growth rate, $\mathrm{d} a / \mathrm{d} N$. Therefore, in order to isolate the microstructural influence on the small crack behavior (and to examine the effect of $R$ or any other variable), it is important to minimize the contributions of external factors on the fluctuation in growth rate in the $\mathrm{d} a / \mathrm{d} N$ vs. $\Delta K$ space. Towards this end, a data reduction method developed by Larsen [41] was used in this study. This technique will be referred to as the crack-length increment method in the remainder of this paper. The method is based on a polynomial fit to crack length $(a)$ vs. cycles $(N)$ data blocks, where the number of data points in a block is varied to satisfy an error criterion [41]. The data block is moved by a prescribed crack length increment (as opposed to point-wise increment), which was taken to be on the order of the microstructural size scale ( $5 \mu \mathrm{m}$, which is on the order of the $\alpha_{p}$ size) in the present study. An illustration of data reduced by this method is given in Fig. 7 where the crack-length increment method is compared to the 3 -point sliding polynomial method. The data shown in the figure is for Ti-6-2-4-6 at the temperature of $260{ }^{\circ} \mathrm{C}$ and $R=-0.5$. Note that 16 small cracks, which initiated from FIB machined micro-notches in two specimens, are represented in Fig. 7.

\section{Results and discussion}

\subsection{Effect of stress-ratio on the small-crack growth behavior}

The effect of $R$ on the small crack growth behavior at $260{ }^{\circ} \mathrm{C}$ is shown in Fig. 8 in terms of $\mathrm{d} a / \mathrm{d} N$ vs. the nominal $\Delta K$. As shown, $R$ of $-0.5,0.05$, and 0.5 were employed. The maximum stress levels applied at these $R$ values are given in Table 1. All small cracks represented in the figure initiated from FIB machined micro-notches. Numbers of such small cracks were 16 (total from two specimens),
7 , and 9 at $R$ of $-0.5,0.05$, and 0.5 , respectively (Fig. 8). A qualitative examination of Fig. 8 suggests that $R$ did not produce a significant influence on the small-crack growth behavior. Similar results were obtained in a separate study on the effect of $R$ on the smallcrack growth regime in another $\alpha+\beta$ titanium alloy, Ti-6-4 [32]. Given that crack-growth lifetime can be very sensitive to the statistical parameters of the small-crack growth behavior [42], from the perspective of probabilistic life prediction, the next questions are: (i) how to probabilistically represent the small-crack growth data for a life prediction analysis, (ii) what is the statistical significance of the differences in small-crack behavior with respect to $R$, and (iii) what is the impact of differences in the statistical parameters on the probabilistic life prediction. These three factors are discussed in the following subsections.

\subsection{Probabilistic representation of the small-crack growth data}

Two approaches to probabilistic modeling of small-crack growth behavior were taken and are illustrated here. The first approach is based on fitting a model to the reduced $\mathrm{d} a / \mathrm{d} N-\Delta K$ data, which requires care in terms of verifying if the model accurately produces the measured crack length vs. cycles ( $a$ vs. $N$ ) data. The second approach is based on using an optimization method to calculate the model parameters that give the best match between the predicted and measured $a$ vs. $N$ data. Both methods are compared in the following subsections, and some considerations that were found to be important in incorporating small-crack growth data in life prediction are highlighted. To study the effect of $R$ on probabilistic life prediction, the latter method, i.e., based on optimization of model parameters, was implemented.

\subsubsection{Method I - fitting a model to the reduced da/dN- $\Delta K$ data}

Choice of the data reduction method is significant if the resulting $\mathrm{d} a / \mathrm{d} N-\Delta K$ data is employed in fitting a model. Particularly in probabilistic life prediction where, in addition to accurately representing individual cracks, the variability in the small-crack growth behavior is quantitatively represented, minimizing the extraneous contributions to the $\mathrm{d} a / \mathrm{d} N$ data assumes added significance. In the method of fitting a model to the reduced $\mathrm{d} a / \mathrm{d} N-\Delta K$ data, it is useful to note that any artifacts in the $a$ vs. $N$ measurements may be further enhanced in the $\mathrm{d} a / \mathrm{d} N-\Delta K$ space as discussed in a recent study [43]. The resulting error is reflected in the fit, which, due to the sensitivity of the crack-growth lifetime to the $\mathrm{d} a / \mathrm{d} N-\Delta K$ representation [42], will lead to an error in life prediction. The crack-length increment method by Larsen [41], described previously, was employed here, which seeks to address the contribution of artifacts in the $a$ vs. $N$ data in the reduced $\mathrm{d} a / \mathrm{d} N-\Delta K$ data.

One objective of the small-crack growth data reduction is to determine the model that represents the $\mathrm{d} a / \mathrm{d} N$ vs. $\Delta K$ relationship. As evident from Fig. 8, a power law is justifiable in this case as, on an average, the small cracks show a linear trend in the $\log (\mathrm{d} a / \mathrm{d} N)$ vs. $\log (\Delta K)$ space. Therefore, a Power-law equation, similar in form to Paris-law [44], was fit to data for individual cracks and can be expressed as:

$\frac{d a}{d N}=e^{c} \Delta K^{n}$

Note that when the power-law coefficient is expressed as $e^{C}, C$ is shown to be distributed normally [45]. A set of values for $C$ and $n$ were thus obtained for each $R$. The distribution in $C$ and $n$ can be approximated by a joint-normal probability density where these two random variables are strongly negatively correlated [45]. Some details of this approach as applied in a different study are given in [35]. The method is illustrated in Fig. 9 with the help of the set of values for $C$ and $n$ at $R=-0.5$. Fig. 9a shows the small-crack growth curves reduced by the crack-length increment method at 

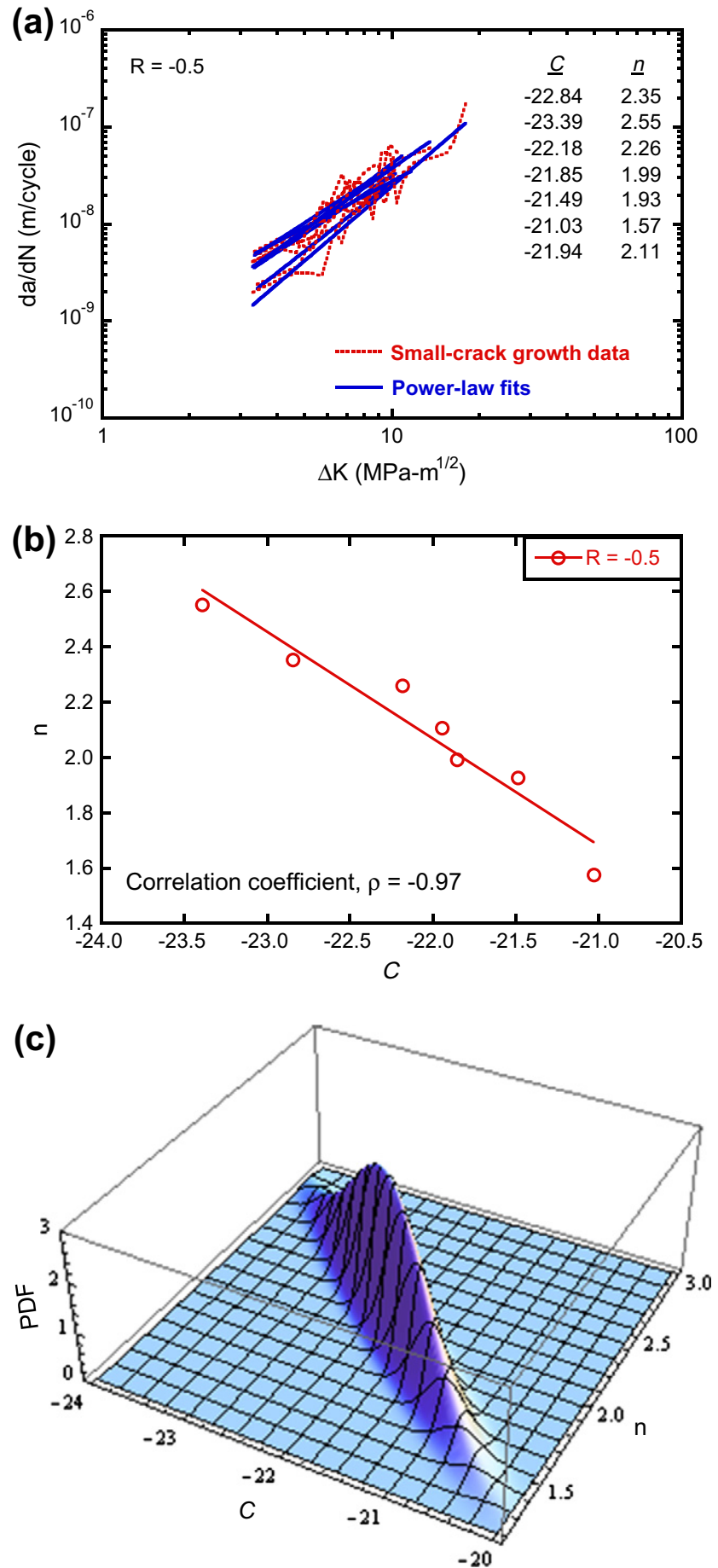

Fig. 9. Probabilistic representation of the small fatigue crack growth data; (a) power-law fits to the small-crack growth curves obtained at $R=-0.5$, (b) illustration of correlation between the variables $C$ and $n$, and (c) joint-normal probability density representing the distribution in the random variables $C$ and $n$ at $R=-0.5$.

$R=-0.5$ and the corresponding power-law fits. Note that only seven curves are shown in Fig. 9a although 16 of the 18 FIB notches (in two specimens) initiated a crack. This down-selection pertains to a final crack length criterion due to the consideration of minimizing the artificial contributions to the statistical parameters of small-crack growth and is explained later. The normal-distribution parameters for $C$ and $n$, based on these 7 curves, were derived using the maximum likelihood estimate (MLE). Fig. 9b illustrates
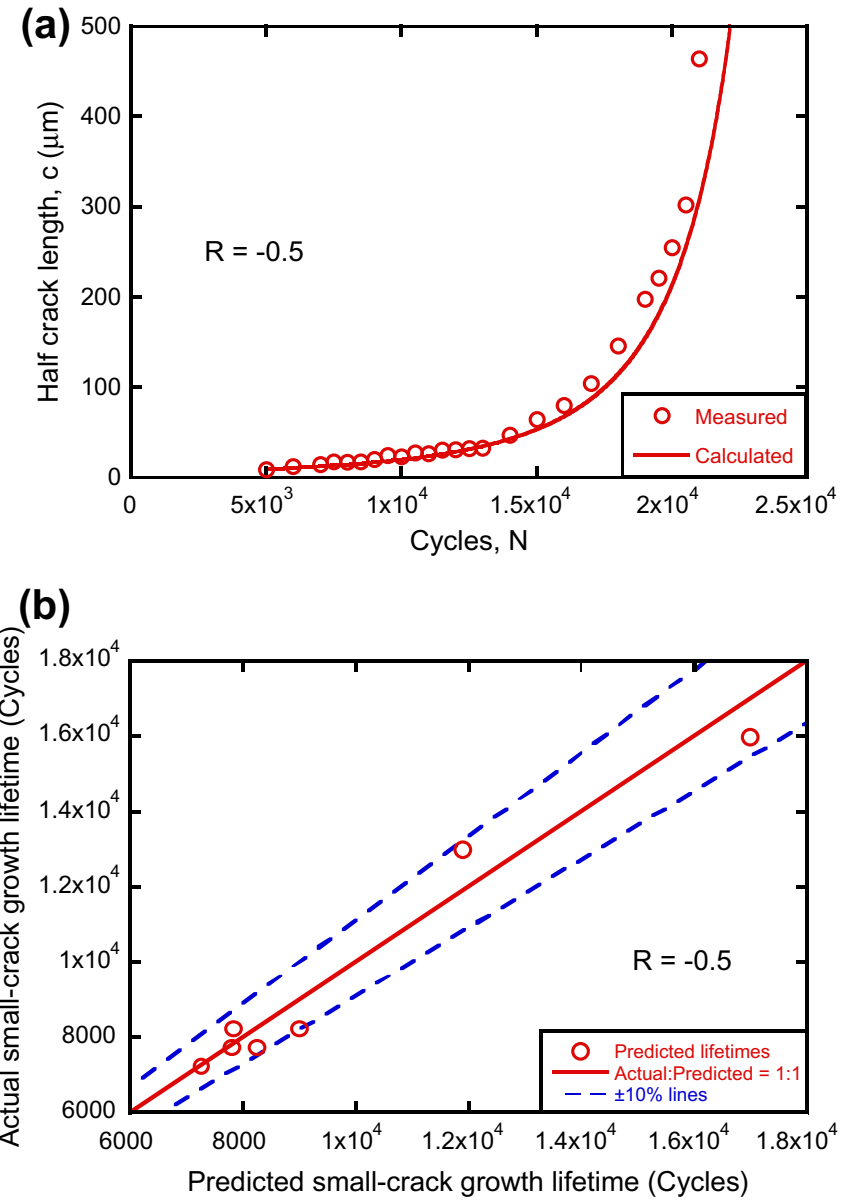

Fig. 10. Testing the accuracy of representing small-crack growth by power-law fit to data reduced by the crack-length increment method; (a) predicted vs. measured $a$ vs. $N$ data for a given crack at $R=-0.5$ and (b) actual vs. predicted small-crack growth lifetimes for cracks at $R=-0.5$.

the correlation between $C$ and $n$. The correlation coefficient, $\rho$ in this case was -0.97 . The joint-normal density representing the two variables is given in Fig. 9c.

Modeling individual small-crack growth curves by a power-law is expected to capture the average growth behavior of a given crack in terms of $\mathrm{d} a / \mathrm{d} N$ vs. $\Delta K$, although the growth rate fluctuates about the average due to microstructural influences. This representation may be justified if the calculated $a$ vs. $N$ based on the modeled behavior reproduces the measured $a$ vs. $N$ data. Additionally, in order to verify the accuracy of the present approach, it is important to confirm that the predicted crack-growth lifetime between a given crack-length interval matches the experimentally observed change in lifetime for the same interval. These factors are demonstrated in Fig. 10. The calculated $a$ vs. $N$ based on a power-law fit to the $\mathrm{d} a / \mathrm{d} N$ vs. $\Delta K$ data using the crack-length increment method of data reduction for a crack at $R=-0.5$ is compared to the measured $a$ vs. $N$ data for the same crack in Fig. 10a. A reasonable agreement between the calculated and measured $a$ vs. $N$ data can be seen from this figure. Next, crack growth lifetimes were calculated for the interval between the first measured crack length (i.e., when a crack was first detected to have grown out of the FIB notches) and the final length for the given crack. The calculated vs. the measured crack-growth lifetime for all cracks included in the probabilistic model at $R=-0.5$ are plotted in Fig. 10b. As shown, the predicted crack growth lifetimes were within $10 \%$ of the measured lifetimes between the respective crack growth intervals. This suggests that 

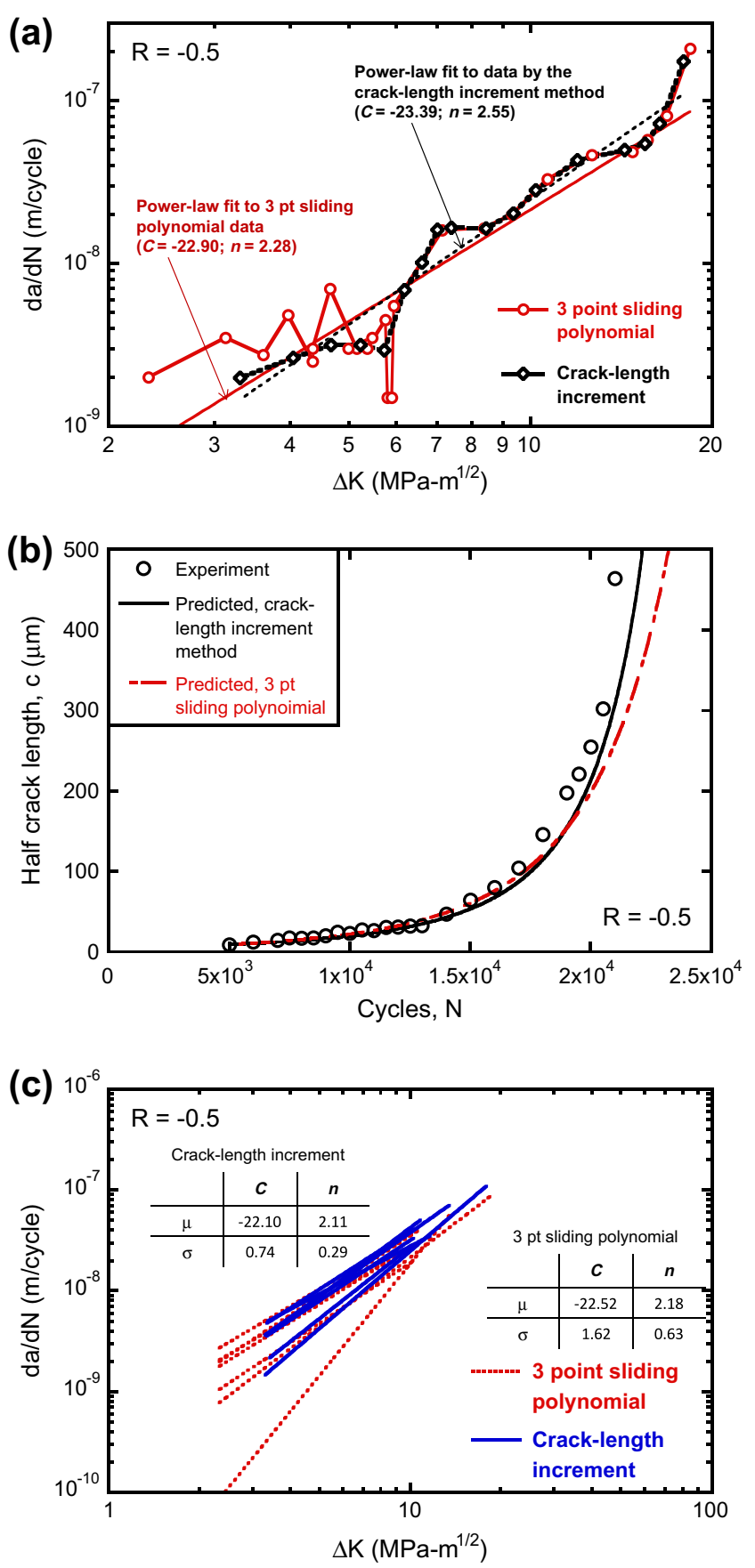

Fig. 11. Effect of the small-crack growth data reduction method on the statistical parameters of $C$ and $n$; (a) illustration of the effect of the method on the power-law fit using a small crack at $R=-0.5$, (b) illustration of the error in the predicted $a$ vs. $N$ data for the same crack as in (a), and (c) illustration of the effect of the data reduction method on the statistical parameters, mean $(\mu)$ and standard deviation $(\sigma)$, of $C$ and $n$ using the data at $R=-0.5$.

this method represents a reasonable treatment of small-crack data for the purpose of probabilistic life prediction.

\subsubsection{Considerations in fitting a model to the $d a / d N-\Delta K$ data}

Variability in the small-crack growth rates, both in terms of the fluctuations in growth rate of a given crack and differences between cracks growing in nominally the same material, is expected due to a strong interaction of small cracks with the local microstructure and the fact that subsurface crack growth may affect the path and velocity of the crack as measured on the specimen surface. The goal here is to minimize artificial contributions to this variability. As alluded to previously, error in the $\mathrm{d} a / \mathrm{d} N-\Delta K$ data can arise from external factors such as data collection frequency and measurement resolution or measurement error. In probabilistic representation, an additional factor that was found important was the final crack length. The first two factors listed above are interrelated, in that the influence of measurement resolution or error will get exacerbated with higher data collection frequency, and is attributed to the fact that the increment in the length of a microstructurally-small crack can be on the order of the resolution of optical measurement or within the range of experimental error. These variables artificially contribute to the fluctuations in the reduced $\mathrm{d} a / \mathrm{d} N$ vs. $\Delta K$ data. The third factor, i.e., the final crack length does not affect the fluctuation in growth rates of the given crack but may artificially distort the statistical parameters of a smallcrack growth model if the model is to be used in prediction of the total crack growth lifetime. These factors are illustrated in the following discussion.

An illustration of the effect of the external contributions, listed previously, to the reduced $\mathrm{d} a / \mathrm{d} N-\Delta K$ data on the probabilistic representation of small-crack growth is given in Fig. 11 with the help of the small cracks measured at $R=-0.5$. The data collection interval at the beginning of this test was 500 cycles, which was increased to 1000 cycles in the intermediate growth-rate period, and then decreased back to 500 cycles towards the end of the test. In Fig. 11a, data reduced by the crack-length increment method is compared to the 3-point sliding polynomial method. Power-law representations of the $\mathrm{d} a / \mathrm{d} N-\Delta K$ data are also shown for each method. In case of the sliding polynomial method, the variables, $C$ and $n$ depend on the frequency of small-crack measurements and the number of points in the polynomial fit and may misrepresent the true average trend in $\mathrm{d} a / \mathrm{d} N$ with respect to $\Delta K$. Although the power-law fits appear similar in Fig. 11a, the difference in the values of $C$ and $n$ by the sliding polynomial method vs. those given by the crack-length increment method can be significant in terms of the crack-growth lifetime prediction. Therefore, it is important to test the goodness of the power-law representation by comparing the predicted $a$ vs. $N$ data to the actual measurements, which is illustrated in Fig. 11b. For this crack, the 3-point sliding polynomial method produces a reasonable prediction of the $a \mathrm{vs}$. $N$ data but the crack-length increment method appears to give a more accurate representation, across the full range of the $a$ vs. $N$ data. The crack-length increment method also gives a relatively better correspondence with the crack-growth lifetime for this crack. For illustration, the measured number of cycles for this crack starting from when it was first observed to grow out of the FIB notch until the final measurement was 16,000 cycles. The power-law parameters by the 3-point sliding polynomial method predicted a crack growth lifetime of 17,981 in the same interval while the crack-length increment method produced a lifetime of 16,983 cycles. The error was about $12 \%$ and $6 \%$, respectively by the 3 -point sliding polynomial and the crack-length increment method.

As mentioned before, the above factors may be further accentuated in a probabilistic model of the small-crack growth behavior when a set of cracks at a given condition is considered. To illustrate this point, power-law fits to the small-crack data set at $R=-0.5$, where data were reduced by the 3-point sliding polynomial method are compared to power-law representations of the $\mathrm{d} a / \mathrm{d} N-\Delta K$ data by the crack-length increment method in Fig. 11c. The statistical parameters of the model variables, listed in the figure, demonstrate the strong influence of the method on these parameters. For example, the mean and standard deviation of $C$ by the 3-point sliding polynomial method were -22.52 and 1.62 respectively. On the other hand, those parameters were -22.10 and 0.74 when the crack-length increment method was used. This difference in 


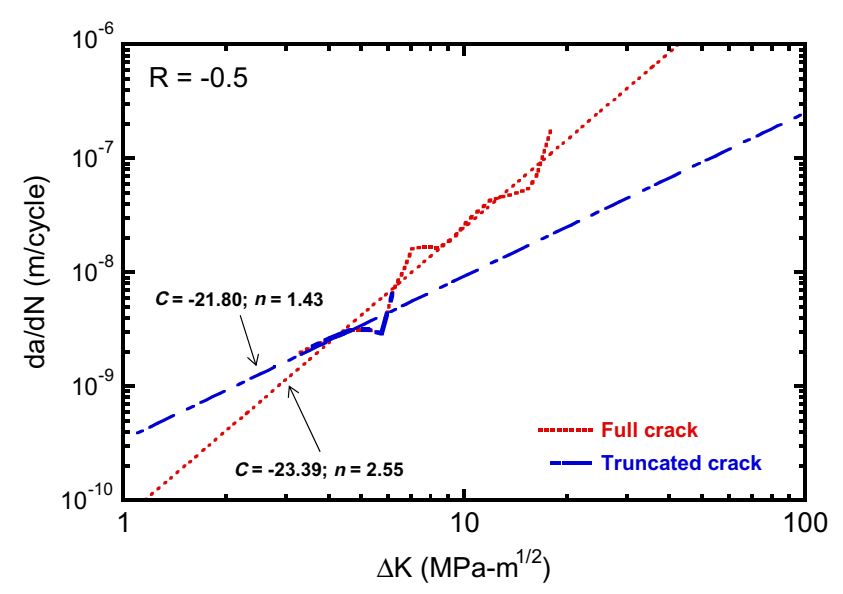

Fig. 12. Illustration of the effect of the crack length at the time of fracture on the fit to the $\mathrm{d} a / \mathrm{d} N$ vs. $\Delta K$ data using a crack at $R=-0.5$.

statistical parameters of $C$ will likely have a significant effect on the predicted lifetime distribution.

The statistical parameters of the small-crack growth variables in a probabilistic representation were also found to be sensitive to the extent of crack growth or the final crack length measurement for a given crack. This is because, if a crack did not grow to a sufficient size relative to the controlling microstructural unit, the power-law fit to the corresponding $\mathrm{d} a / \mathrm{d} N-\Delta K$ data may be biased by a local snapshot of the growth behavior, which can be very different from the overall trend if that crack had grown to a sufficiently larger size with respect to the microstructure. This factor can misrepresent the statistical parameters of the small-crack growth model variables if the model is to be used in calculation of the distribution in the total crack-growth lifetime, i.e., until fracture. In other words, if the objective were to calculate the distribution in lifetime only up to a certain crack length, then it would be appropriate to use the data until the given crack size. In the present study, however, it is necessary to represent the full trend of a crack. This requires that, only those cracks that have grown past certain number of microstructural units such that their overall trends will not vary upon further growth, be considered in the model representation. This is illustrated in Fig. 12, where the same crack as in Fig. 11a is shown. The first measurement of this crack was $2 c=18 \mu \mathrm{m}$ and the final measurement was $2 c=928 \mu \mathrm{m}$, which corresponded to a $\Delta K$ of about $23 \mathrm{MPa} \sqrt{ } \mathrm{m}$. The power-law fit to the $\mathrm{d} a / \mathrm{d} N$ vs. $\Delta K$ data is shown in the figure. For the sake of argument, if other cracks in the specimen were more dominant, then the final measurement for this crack just before fracture would have been smaller. To illustrate the point, the $\mathrm{d} a / \mathrm{d} N-\Delta K$ data assuming that the crack length at the time of failure was only $70 \mu \mathrm{m}(\Delta K \sim 6 \mathrm{MPa} \sqrt{ } \mathrm{m})$ is shown in Fig. 12. The corresponding power-law fit is very different from when the crack grew to a larger length, as it is skewed by a local trend, which is not representative of the true behavior across the full range of crack length. The values of $C$ for the full and the truncated crack were -23.39 and -21.80 respectively (Fig. 12), which is a significant difference in terms of lifetime calculation. The error due to this factor can be minimized if cracks smaller than a critical size are not included in the probabilistic representation of the small-crack growth regime. As mentioned above, ideally, the critical crack length should correspond to the $\Delta K$ beyond which a fit to the data is largely independent of the crack length. The crack size corresponding to the transition to a large crack may be a reasonable critical length, as it can be suggested that once a crack has transitioned to a large crack, its overall trend is already developed and a model represen- tation of the data will likely be minimally influenced by further increase in length beyond the transition point. This criterion was adopted here, and only cracks that had grown to the half surface crack length of at least $100 \mu \mathrm{m}$ (which is about 20 times the $\alpha_{\mathrm{p}}$ size) at the time of specimen fracture were considered in the probabilistic representation. This is based on the study by Lankford, who reported that in many materials the transition from the small to large-crack behavior corresponded to about 10-20 times the controlling microstructural unit size [46]. It should be noted that, while the final crack length criterion is necessary to obtain accurate statistical parameters in calculation of total small-crack growth lifetimes, this may bias the population of cracks used in the analysis towards those that exhibited faster growth. This is an artifact of multiple propagating cracks in each specimen due to multiple FIB notches, which suppresses the full $a$ vs. $N$ information from some slow growing cracks. An ideal case will be when each specimen has single notch that initiates the only propagating crack. Then, if a sufficient number of tests are conducted, a more complete range of growth rates can be represented in the model of small-crack growth. In terms of probabilistic life prediction, the influence of this artifact will be to produce predictions that are conservative with respect to the actual distributions.

It is useful to note that, in many cases, a standard data reduction method such as sliding polynomial may be sufficient in probabilistic life prediction but the reduced data will be dependent upon the frequency of measurements and the number of points in a polynomial fit, which will influence the statistical parameters in a probabilistic representation. In some cases (depending on the amount of data), a higher-point sliding polynomial method may yield a similar result as the crack-length increment method used here. However, an important feature of the latter method is that it provides a consistent $\mathrm{d} a / \mathrm{d} N-\Delta K$ data independent of experimental variables such as data collection frequency and measurement error as long as an appropriate crack-length increment is adopted in the analysis. As discussed above, a crucial metric for the accuracy of a smallcrack growth model is to compare the $a$ vs. $N$ behavior predicted by the model representation to the measured $a$ vs. $N$ data. It can be said that, to the extent that a model limits the error in the predicted $a$ vs. $N$ to an acceptable level, it might be applicable in probabilistic life prediction analysis.

\subsubsection{Method II - method of optimization of the small-crack growth model parameters}

As illustrated above, fitting a model to the $\mathrm{d} a / \mathrm{d} N-\Delta K$ data by the crack-length increment method produced crack-growth lifetimes within $\pm 10 \%$ of actual lifetimes, which may be an acceptable level of error (Fig. 10). However, a more rigorous approach can be to calculate the optimal model parameters that will give the best match between the predicted and the measured $a$ vs. $N$ data. This method can further improve the agreement between the predicted and actual crack growth lifetimes since the objective is to accurately represent the measured $a$ vs. $N$ data rather than fitting to the reduced $\mathrm{d} a / \mathrm{d} N-\Delta K$ data, which is sensitive to measurement errors.

As discussed before, a power-law model (Eq. (2)) is a reasonable representation of the overall trend of the small-crack growth behavior in the $\mathrm{d} a / \mathrm{d} N-\Delta K$ space. The optimization problem, in this case, is to find the optimal values of the power-law variables, $C$ and $n$ that will minimize the error between the predicted and the measured $a$ vs. $N$ data. The cost function, $f(C, n)$ that has to be minimized was formulated as the least squares error between the predicted and the measured $a$ vs. $N$ data, given by:

$f(C, n)=\sum_{i=N_{1}}^{N_{\mathrm{n}}}\left(a_{\text {pred }}-a_{\text {meas }}\right)_{\mathrm{i}}^{2}$ 

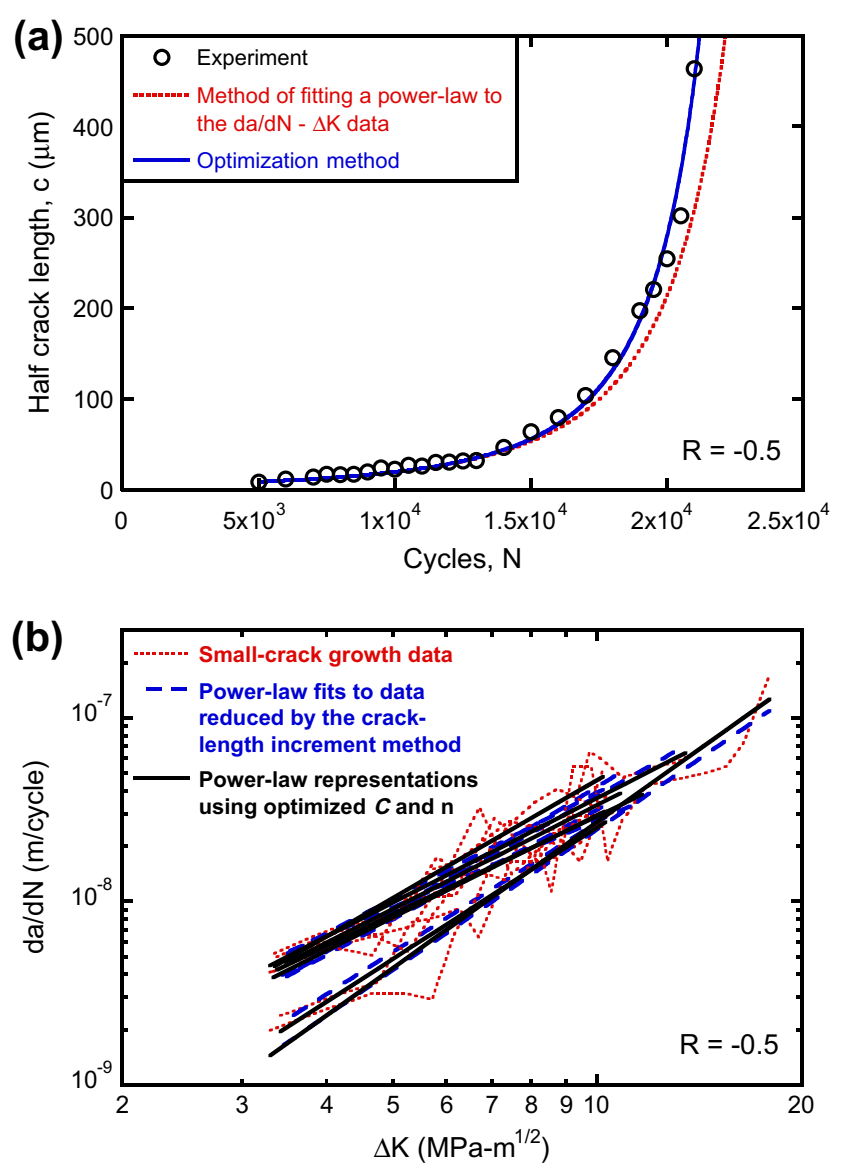

(c)

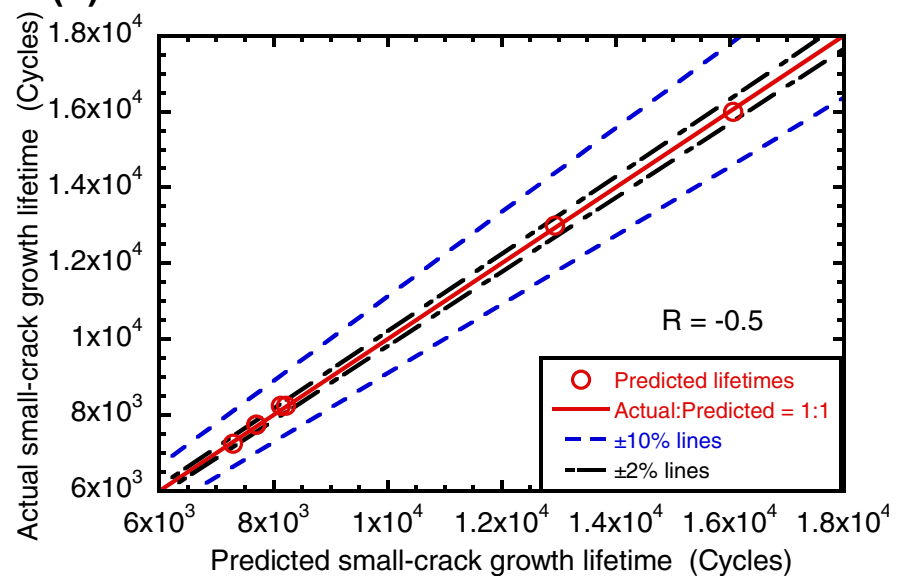

Fig. 13. Demonstration of the method of optimization of the small-crack growth model parameters with respect to the measured $a$ vs. $N$ data; (a) Comparisons of measured and predicted $a$ vs. $N$ using the crack-length increment data reduction approach and the optimization method for a crack at $R=-0.5$, (b) Optimized power-law representations of small-crack growth curves compared to fits to $\mathrm{d} a / \mathrm{d} N-\Delta K$ data reduced using the crack-length increment method for cracks at $R=-0.5$, and (c) actual vs. predicted crack growth lifetimes for cracks at $R=-0.5$ using the optimized model representations of small-crack growth.

where $a_{\text {pred }}$ and $a_{\text {meas }}$ are the predicted and the measured half crack length, respectively. $N_{1}$ corresponds to the cycle count at which the crack was first detected and $N_{n}$ represents the cycle count at the final measurement. The summation is performed over all cycle counts, starting with $\mathrm{N}_{1}$, at which crack length measurements were recorded. Note that a weighted least squares error [47] can also be explored as a formulation for the cost function, which may be more appropriate when the data collection frequency is high and the data
Table 2

Results of the Student's $t$-test on data sets of $C$ for various $R$ pairs.

\begin{tabular}{lllll}
\hline$R$ pairs & Hypothesis & $t$ stat & $P$-value (two-tail) & $t_{\text {critical }}$ \\
\hline 0.05 and 0.5 & Null & -2.19 & 0.07 & 2.45 \\
0.05 and -0.5 & Null & -2.41 & 0.04 & 2.26 \\
0.5 and -0.5 & Null & -0.59 & 0.56 & 2.26 \\
\hline
\end{tabular}

Table 3

Populations of $C$ and $n$ values obtained by the crack length increment method and the optimization method at $R=-0.5$

\begin{tabular}{llllll}
\hline Crack \# & \multicolumn{2}{l}{$\begin{array}{l}\text { Power-law fit to data by crack length } \\
\text { increment method }\end{array}$} & & \multicolumn{2}{l}{$\begin{array}{l}\text { Optimization } \\
\text { method }\end{array}$} \\
\cline { 2 - 3 } \cline { 5 - 6 } \cline { 5 - 6 } & $C$ & $n$ & & \\
\hline 1 & -22.84 & 2.35 & -22.98 & 2.38 \\
2 & -23.39 & 2.55 & -23.51 & 2.64 \\
3 & -22.18 & 2.26 & -21.55 & 1.88 \\
4 & -21.85 & 1.99 & -21.60 & 1.85 \\
5 & -21.49 & 1.93 & -21.82 & 2.14 \\
6 & -21.03 & 1.57 & -21.44 & 1.78 \\
7 & -21.94 & 2.11 & -21.49 & 1.89 \\
\hline
\end{tabular}



Fig. 14. Actual vs. predicted crack growth lifetimes for cracks at all $R$ employed in this study using the optimized model representations of small-crack growth.

exhibits non-uniform variance with respect to the cycle count. A Mathematica ${ }^{\mathrm{TM}}$ script was written to perform the optimization calculation in which the Nelder-Mead numerical optimization method was implemented. The range of values of $C$ and $n$ obtained by the first approach, i.e., fitting the $\mathrm{d} a / \mathrm{d} N-\Delta K$ data, were used as the initial variable search space in the optimization routine.

An example of the predicted $a$ vs. $N$ data using the values of $C$ and $n$ given by the optimization method is shown in Fig. 13a for a crack at $R=-0.5$ (which is the same crack as shown in Fig. 10a). For comparison, the predicted $a$ vs. $N$ using the $C$ and $n$ values from fitting a power-law to the $\mathrm{d} a / \mathrm{d} N-\Delta K$ data reduced by the crack length increment method is also included. It is not surprising that the optimized model produces a better agreement between the predicted and the measured $a$ vs. $N$ data. The power-law representations of small-crack curves at $R=-0.5$ based on the optimal $C$ and $n$ values are compared to those based on the first approach in Fig. 13b. The corresponding populations of $C$ and $n$ values by the two methods are given in Table 3. As shown, the model based on optimized variables does not differ significantly from the power-law fits to data reduced by the crack-length increment method, indicating that only small changes in the values given by the first approach are required to attain optimum 



Fig. 15. Crack-initiation size distribution in Ti-6-2-4-6 at $260^{\circ} \mathrm{C}$; (a) a crackinitiation site showing a faceted $\alpha_{\mathrm{p}}$ particle at the crack origin $\left(\sigma_{\max }=860 \mathrm{MPa}\right.$, $R=0.05$ ) and (b) The crack initiation size distribution at $R=0.05$ shown in the lognormal cumulative distribution function space.

variables. In Fig. 13c, the actual vs. predicted small-crack growth lifetimes using the optimized $C$ and $n$ are plotted. Once again, the actual lifetime represents the total cycles expended between when the given crack was first detected to have grown out of the FIB notch and the final measurement. The predicted value corresponds to the crack-growth lifetime from the first measured crack length to the final crack length, calculated using the optimized values of $C$ and $n$ obtained for the given crack. As expected, an improved agreement between the actual and predicted values is achieved when compared to Fig. 10b. As shown, in this case, the predictions by the optimization method were within $\pm 2 \%$ of the actual values compared to $\pm 10 \%$ by the first method. As stated before, the distributions in $C$ and $n$ at various Rs as given by the optimization method were used in the subsequent probabilistic life prediction analysis. A plot of the actual vs. predicted small-crack growth lifetimes given by the optimization method at all three $R$ values is shown in Fig. 14. As illustrated by the figure, at each $R$, the optimization method produced predictions within $\pm 2 \%$ of the actual small-crack growth lifetimes.

\subsection{Statistical significance}

To determine the statistical significance of the effect of $R$ on the small-crack growth behavior, a $t$-test [48] was employed, which is

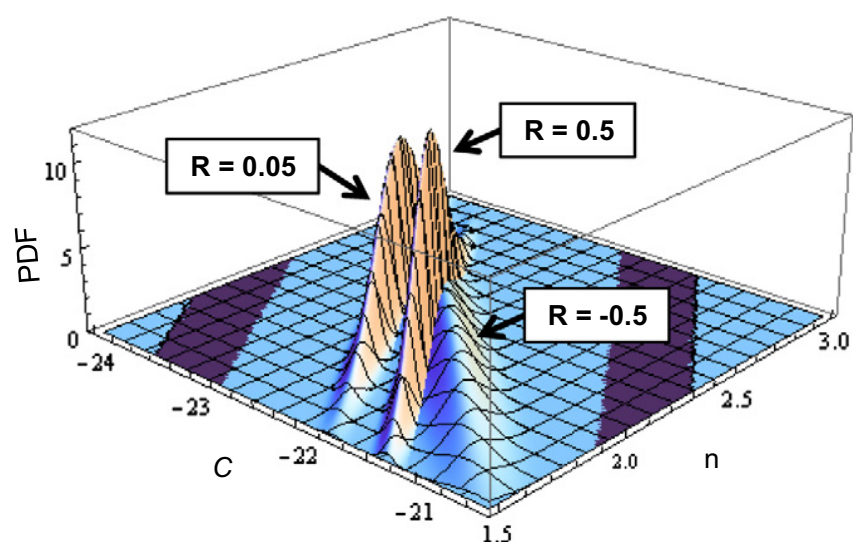

Fig. 16. Joint normal distributions of $C$ and $n$ at $R=-0.5,0.05$, and 0.5 used in probabilistic life prediction.

a standard technique to assess if two data sets have statistically different means. Since the mean and variance of the simulated crack-growth lifetime distribution were found to be most sensitive to $C$ [42], the test was performed on this random variable. Only the populations of cracks at each $R$ that were employed in the probabilistic representation of small crack growth were tested. A twosample $t$-test assuming unequal variances [48] was used. The results of this test are given in Table 2. The $t$ value for the null hypothesis between data pairs at $R=0.05$ and $0.5, R=0.05$ and -0.5 , and $R=0.5$ and -0.5 were $-2.19,-2.41$, and -0.59 respectively (Table 2 ). The corresponding two-tail $P$ values (i.e., the probability that the $t$ value is less than the critical $t$ ) were $0.07,0.04$, and 0.56 respectively. One interpretation of this test can be, that there is a low probability that the populations of $C$ at $R=0.05$ and 0.5 and those at $R=0.05$ and -0.5 have statistically the same mean. Also, there is moderate probability that the populations at $R=0.5$ and -0.5 have statistically different means. Given that the calculated lifetime distribution is very sensitive to the mean and standard deviation of $C$, the next question is whether these differences are significant in terms of life prediction, as is discussed in the next sub-section.

\subsection{Effect on probabilistic life prediction}

\subsubsection{The life prediction method}

Previous studies on life-limiting fatigue behavior in several structural materials have shown that the lifetime distribution separates into two populations, termed as mean-dominating and lifelimiting populations $[29,35,36]$. The life-limiting population is defined as the short-lifetime population that follows a different trend than the mean-dominating population with respect to stress level or any other variable. More specifically, the mean behavior diverged (or converged) with respect to the life-limiting behavior as a function of microstructure, stress level, temperature, etc. $[29,35,36]$. The probability of occurrence of the life-limiting failures varied as a function of these variables. For example, while all failures belonged to a single distribution at the higher stress levels, the lifetimes separated into two modes at lower stress levels, and the frequency of occurrence of points in the short-lifetime population (considered as the life-limiting population) decreased with a decrease in the stress level [36]. Through probabilistic simulation of the crack growth lifetime, it was shown that the distribution in the life-limiting points can be modeled by the small and long crack growth lifetime distribution for cracks initiating from the controlling microstructural scale $[35,36]$. The simulation was performed by the Monte Carlo method where the input random 
Table 4

Statistical parameters of small-crack growth model variables obtained using the optimization method.

\begin{tabular}{|c|c|c|c|c|c|c|c|}
\hline \multirow[t]{2}{*}{ Random variable } & \multirow[t]{2}{*}{ Distribution } & \multicolumn{2}{|l|}{$R=-0.5$} & \multicolumn{2}{|l|}{$R=0.05$} & \multicolumn{2}{|l|}{$R=0.5$} \\
\hline & & $\mu$ & $\sigma$ & $\mu$ & $\sigma$ & $\mu$ & $\sigma$ \\
\hline$a$ & Lognormal & 2.29 & 0.27 & 2.29 & 0.27 & 2.29 & 0.27 \\
\hline$C$ & Joint-normal $^{\mathrm{a}}$ & -22.06 & 0.77 & -23.04 & 0.44 & -22.29 & 0.39 \\
\hline$n$ & Joint-normal $^{\mathrm{a}}$ & 2.08 & 0.30 & 2.31 & 0.28 & 2.11 & 0.24 \\
\hline
\end{tabular}

a The correlation coefficient, $\rho$ between $C$ and $n$ were $-0.97,-0.99$, and -0.99 at $R=-0.5,0.05$, and 0.5 respectively.



Fig. 17. Predicted life-limiting failure distribution at $R=0.05$ and $260{ }^{\circ} \mathrm{C}$.

variables were: (i) the crack-initiation size, (ii) the small-crack growth variable, $C$, and (iii) and the small-crack growth variable, $n$.

The crack-initiation size was modeled by the lognormal distribution, the parameters of which were derived by MLE based on a population of crack-initiation sizes measured in fractured fatigue specimens. For example, a typical crack initiation site in duplex Ti-6-2-4-6 at $260^{\circ} \mathrm{C}$ is shown in Fig. 15a [49]. Crack initiation in this alloy is accomplished by formation of a crystallographic facet across a (or a few) primary- $\alpha$ particle, as indicated in the figure. While subsurface failures were observed under certain loading conditions, the life-limiting failures were always associated with surface crack initiation. Areas of the crack-initiation facets were measured in a number of fractured specimens, and the distribution in the equivalent crack-initiation depth, $a$ (i.e., radius of a semicircle with the same area as the crack-initiation facet(s)) at $R=0.05$ is shown in Fig. 15b in lognormal cumulative distribution function (CDF) space. The corresponding lognormal fit to the data, which was used as an input to the probabilistic model, is also shown. The crack-initiation size distribution was assumed to be invariant with respect to $R$, which will be the case if, in life-limiting specimens, the crack-initiation mechanism involved facet formation in primary- $\alpha$ particles at the surface. However, this was not verified at all stress ratios.

The two random variables associated with the small-crack growth, $C$ and $n$, were described previously. A set of values of $C$ and $n$ were obtained at each $R$, which corresponded to the optimal values given by the method of optimization of the small-crack growth model with respect to the measured $a$ vs. $N$ data. The distribution in $C$ and $n$ were modeled by the joint-normal probability distribution function, the parameters of which were derived by MLE, as discussed before. The joint probability densities representing $C$ and $n$ at $R=-0.5,0.05$, and 0.5 that were used in the probabilistic model are shown in Fig. 16 and the corresponding parameters are given in Table 4. Note that the correlation coefficient, $\rho$, which, in this case, borne from the optimized representations of small-crack growth were $-0.97,-0.99$, and -0.99 respectively at $R=-0.5,0.05$, and 0.5 .


Fig. 18. Influence of the effect of $R$ on the small-crack growth regime on the prediction of probabilistic lifetime limits. Predicted crack-growth lifetime distributions and B0.1 lifetimes at (a) $R=-0.5$, (b) $R=0.05$, and (c) $R=-0.5$.

From the perspective of predicting a limiting fatigue lifetime for design purposes, the above model provides a mechanism-based method to account for the worst-case fatigue failure distribution, 
almost independent of both the amount of fatigue data and whether a life-limiting point is captured by the lifetime data from $S-N$ tests. For illustration, in Fig. 17, the predicted life-limiting distribution is compared to the experimental data for the case of $R=0.05$. The predicted distribution consists of 10,000 Monte Carlo predictions. The plot represents the CDF based on the lognormal distribution. As shown, the experimental points display a step-like morphology in the CDF space, indicating a superposition of two distributions. The three shortest lifetime points, which form the lower part of the step, are considered as belonging to the life-limiting population. The predicted distribution had a similar slope to the life-limiting points when those are plotted as a separate distribution (Fig. 17). However, although the predicted distribution covers the range of lifetimes of the life-limiting points, it is conservative with respect to the average behavior of the life-limiting population. This discrepancy could be due to the factors that only a limited number of life-limiting observations are being compared to the simulation and that a very small number of cracks ( 4 cracks that grew to $a>100 \mu \mathrm{m}$ at $R=0.05$ ) were used to define the input distributions of the small-crack growth random variables, which may not capture the full statistics of the small-crack growth behavior. Also, as discussed previously, the method of using single specimen to characterize multiple cracks may introduce a bias in the analysis towards faster cracks since the full crack-growth trend from slower cracks in the same specimen are suppressed. Nevertheless, the model appears to produce a conservative estimate, within $1.5 \times$ of the life-limiting distribution, and the slope (variance) of the prediction is in excellent agreement with that of the life-limiting data. If the probabilistic lifetime limit is taken as the 1 in 1000 (termed as the B0.1 lifetime) probability of failure, the predicted lifetime limit at $R=0.05$ was about 12,856 cycles, as indicated in the figure. The present study employed this probabilistic life-prediction method with a goal to quantify the importance of the differences in the small-crack growth behavior as a function of $R$ on the probabilistic lifetime limit.

\subsubsection{Effect of $R$ on probabilistic lifetime limit}

The method described above was used to predict the life-limiting distributions at the three $R$ values, which are compared in Fig. 18. As stated before, the same crack-initiation size distribution was used for all $R$ values. Since the predictions also include the effect of the applied stress amplitude on lifetime, in order to represent the true effect of the small-crack growth differences on life prediction, three cases were considered. In each case, a baseline loading condition was chosen, while the effect of employing the small-crack behavior at various $R$ values on the predicted distributions was studied. In other words, if the differences between the small-crack growth behaviors with respect to $R$ were insignificant, the predicted distributions at a given loading condition should be very similar. Fig. 18a-c shows predictions for the loading parameters corresponding to the applied $R$ of $-0.5,0.05$, and 0.5 , respectively. As shown, in each of the three cases, the small-crack data employed in the model has a significant impact on the predicted distributions. This can be further illustrated by the B0.1 lifetimes, which are indicated in Fig. 18a-c, and show differences ranging from $-56 \%$ to $+72 \%$ with respect to the baseline condition. Therefore, in the present problem, the differences in the statistical parameters of the small-crack growth with respect to $R$ are significant from a life-prediction perspective.

The above analysis demonstrates that, although a subjective examination of the present small-crack growth data suggests an insignificant effect of $R$, the effect cannot be ignored in probabilistic life prediction and particularly in probabilistic life limits. This also emphasizes the need for ensuring that the modeled $\mathrm{d} a / \mathrm{d} N-$ $\Delta K$ relationship accurately reflects the measured $a$ vs. $N$ data. It can be said that the small-crack growth is a very important domain of fatigue, both from the consideration of predicting life-limiting failures and due to the sensitivity of the predictions to the smallcrack growth parameters. Therefore, the small-crack regime needs to be accounted for in probabilistic life prediction, but care is required in terms of model representation of small-crack growth. In this regard, the method of optimizing the small-crack growth model with respect to the measured $a$ vs. $N$ data may provide a means to enable the incorporation of the small-crack regime in life prediction models.

\section{Conclusions}

The following main conclusions can be drawn from this study:

(1) When employing the small-crack growth data in probabilistic life prediction, extraneous factors that may introduce artificial contributions to the statistical parameters of the small-crack growth model variables should be minimized, and the model representation of the $\mathrm{d} a / \mathrm{d} N$ vs. $\Delta K$ relationship must be evaluated against predicted vs. measured $a$ vs. $N$ data. Towards this, a method of optimization of the small-crack growth model parameters, that minimizes the error between the predicted and the measured $a$ vs. $N$ data, is proposed. This method was applied to the small-crack growth data in Ti-6-2-4-6 at various values of stress ratio, $R$. A power law model was used to represent the small-crack growth rate vs. $\Delta K$ relationship, where the parameters, $C$ and $n$, of the model were computed by the optimization method. By measuring multiple cracks at each $R$, distributions in $C$ and $n$ were obtained for the probabilistic analysis.

(2) The probabilistic predictions revealed that, although the effect of $R$ on the small-crack growth behavior appeared qualitatively insignificant, the impact of the statistical differences with respect to $R$ was significant on the probabilistic lifetime limit. The lifetime corresponding to the probability of failure of $0.1 \%$ (i.e., the B0.1 lifetime) varied in the range of -56 to $+72 \%$ with respect to the baseline predictions when the effect of $R$ on the small-crack growth was included.

\section{Acknowledgements}

This work was performed at the Air Force Research Laboratory, Materials and Manufacturing Directorate, AFRL/RXCM, WrightPatterson Air Force Base, OH. The financial support of the Air Force Office of Scientific Research under the LRIR Task 11RX01COR, Dr. David Stargel, Program Manager, is gratefully acknowledged. The authors also acknowledge the valuable assistance of Mr. Eric Burba with the small-crack growth experiments.

\section{References}

[1] Dowling NE, Calhoun CA, Arcari A. Fatigue Fract Eng Mater Struct 2009;32:163-79.

[2] Cowles BA. Int J Fract 1996;80:147-63.

[3] Larsen JM, Worth BD, Annis CG, Haake FK. Int J Fract 1996;80:237-55.

[4] Bussu G, Irving PE. Int J Fatigue 2003;25:77-88.

[5] John R, Jata KV, Sadananda K. Int J Fatigue 2003;25:939-48.

[6] McClung RC. Fatigue Fract Eng Mater Struct 2007;30:173-205.

[7] Mutoh Y, Fair GH, Noble B, Waterhouse RB. Fatigue Fract Eng Mater Struct 1987;10:261-72.

[8] Walker K. ASTM STP 462. Am Soc Test Mater 1970:1-14.

[9] Ritchie RO, Knott JF. Acta Metall 1973;21:639-48.

[10] Ravichandran KS, Jha SK. In: Boyer RR, Eylon D, Lutjering G, editors. Fatigue behavior of titanium alloys. Warrendale, PA (USA): TMS; 1999. p. 57-73.

[11] McEvily AJ, Ritchie RO. Fatigue Fract Eng Mater Struct 1998;21:847-55.

[12] Suresh S, Ritchie RO. Eng Fract Mech 1983;18:785-800.

[13] Gray III GT, Williams JC, Thompson AW. Metall Trans A 1983;14A:421-33. 
[14] Dubey S, Soboyejo ABO, Soboyejo WO. Acta Mater 1997;45:2777-87.

[15] Jha SK, Ravichandran KS. Metall Mater Trans A 2000;31:703-14.

[16] Beevers CJ. Met Sci 1977;11:362-7.

[17] Vasudevan AK, Sadananda K, Louat N. Mater Sci Eng A 1994;A188:1-22.

[18] Boyce BL, Ritchie RO. Eng Fract Mech 2001;68:29-147.

[19] Morrissey RJ, McDowell DL, Nicholas T. Int J Fatigue 1999;21:679-85.

[20] Kujawski D. Int J Fatigue 2001;23:S239-46.

21] Suresh S, Ritchie RO. Int Mater Rev 1984;29:445-75.

[22] Lankford J, Davidson DL, Chan KS. Metall Trans A 1984;15A:1579-88.

[23] Miller KJ. Fatigue Fract Eng Mater Struct 1982;5:223-32.

[24] Ritchie RO, Lankford J. Mater Sci Eng 1986;84:11-6.

[25] Taylor D, Knott JF. Fatigue Fract Eng Mater Struct 1981:4:147-55.

[26] Hudak Jr SJ. J Eng Mater Technol 1981;103:26-35.

[27] Caton MJ, Jones JW, Mayer H, Stanzl-Tschegg S, Allison JE. Metall Mater Trans A 2003;34A:33-41.

[28] Newman Jr JC, Phillips EP, Swain MH. Int J Fatigue 1999;21:109-19.

[29] Jha SK, Caton MJ, Larsen JM. In: Reed RC, Green KA, et al., editors. Superalloys 2008. Warrendale, PA (USA): TMS; 2008. p. 565-572.

[30] Caton MJ, Jha SK. Int J Fatigue 2010;32:1461-72.

[31] Christodoulou L, Larsen JM. J Met 2004;56:15-9.

[32] Caton MJ, John R, Porter WJ, Burba ME. Int J Fatigue 2012;38:36-45.

[33] Ritchie RO, Boyce BL, Campbell JP, Roder O, Thompson AW, Milligan WW. Int Fatigue 1999;21:653-62.

[34] McCarver JF, Ritchie RO. Mater Sci Eng 1982;55:63-7.
[35] Jha SK, Caton MJ, Larsen JM. Mater Sci Eng A 2007;468-470:23-32.

[36] Jha SK, Larsen JM, Rosenberger AH. Eng Fract Mech 2009;76:681-94.

[37] Goodman J. Mechanics applied to engineering. London: Longmans, Green, and Co.; 1899.

[38] Nicholas TC, Zuiker JR. Int J Fract 1996;80:219-35.

[39] Swain MH. In: Larsen JM, Allison JE, editors. Small-crack test methods, ASTM STP 1149. American Society for Testing and Materials; 1992. p. 34-56.

[40] Raju IS, Newman JC. In: Underwood JH, Chait R, Smith CW, et al., editors. Fracture mechanics, ASTM STP 905, vol. 17. Philadelphia: American Society for Testing and Materials; 1986. p. 789-805.

[41] Larsen JM, Underwood JH, Chait R, Smith CW, et al., editors. Fracture mechanics, ASTM STP 905, vol. 17. Philadelphia: American Society for Testing and Materials; 1986. p. 226-238.

[42] Jha SK, Millwater HR, Larsen JM. Fatigue Fract Eng Mater Struct 2009;32:493-504.

[43] Xue Y. Int J Fatigue 2010;32:1210-9.

[44] Paris PC, Erdogan F. J Basic Eng 1963;85:528-33.

[45] Annis C. J ASTM Int 2004;1:3-14.

[46] Lankford J. Fatigue Fract Eng Mater Struct 1985;8:161-75.

[47] Carroll RJ, Ruppert D. Transformation and weighting in regression. New York: Chapman and Hall; 1988.

[48] Welch BL. Biometrika 1947;34:28-35.

[49] Jha SK, John R, Larsen JM. Metall Mater Trans A 2009;40:2675-84. 